\title{
On a Woodland Sedge
}

\author{
Steven N. Handel
}

S o often driven by interest in the rare species or the iconic animal, restoration ecology can give short shrift to the important, the dull species, although these can be common in our habitats. Consider the noncharismatic sedges in the genus Carex. They are abundant in wetlands, woodlands, meadows, and arctic habitats. Often they are the most abundant plants in numbers and biomass. In North America, we regularly use a few members of the genus in freshwater wetland borders, scattered within the mixture of adjacent area herbs. Even prairie restorations emphasize wildflowers and native grasses, not sedge species which are part of the historic biodiversity.

They may be in the Cyperaceae family, but to most people, Carex species are wallflowers, lacking any distinct personality or attractiveness to the eye in color or threedimensional structure. Perhaps this is because the leaves, varying in width from 2 to almost $30 \mathrm{~mm}$ and in subtle shades of green, are so difficult to discriminate throughout the year. For most workers, one needs the fruiting body, the peculiar perigynium, which can be available for study for only a few weeks of the year. Seemingly as ephemeral as the morning dew, how do you use the fruits to identify sedges when they all look oh so similar? But hidden within this superficial dullness is a remarkable diversity and ecological importance. Can we now please celebrate the specialness of the mundane?

There are so many sedge species. Carex contains perhaps 2,300 species scattered from the high arctic to wet ditches in subtropical regions. Within any one habitat, we may find dozens of species within the genus Carex, a challenge to theoretical ecologists wanting to discriminate functional differences among sympatric congenerics. MacArthur's famous warblers had real niche differences in the coniferous forest, but he only worked with five sympatric species. Studies within Carex have shown that niche diversity can be identified along dispersal and environmental gradients as well as functional and phylogenetic constraints. In vertebrates, we often look at bill shape and size and dentition diversity to define niche space. In sedges the critical axes may be obscure, but they are no less important. While many temperate woodlands have dozens of Carex species,

Ecological Restoration Vol. 33, No. 4, 2015

ISSN 1522-4740 E-ISSN 1543-4079

C2015 by the Board of Regents of the University of Wisconsin System. all too often even careful community ecology studies lump this biodiversity into one narrow pile labeled "Carex spp." This is the ultimate denial of biological specificity. Gross morphological similarity drives gross indifference to ecological function and personality. Restorationists must avoid this trap.

Carex species have wide variation on the central theme of each species' perigynia. These each are single seeds wrapped in an ovary wall wrapped in a closed bract. How simple. But some bracts have sharp prongs, allowing them to catch on to passing fur and feathers, then dispersed by passing vertebrates. Other perigynia are expanded like green balloons and allow the seed to be carried by the water currents to new wetland areas. Some have large fatty bases, the famed elaiosomes of ant-dispersed species. Here the sedge species co-opt the social behavior of ant colonies. Workers are attracted to the lure of the lipid on the sedge fruit resting on the forest floor, then carry these back to the larva in the nest. The fat is eaten off from the diaspores, then the seed, unharmed, is deposited in the colony's refuse pile where it can germinate, nurtured by the organic matter around it. Some ant workers have been seen carrying sedge seeds over $80 \mathrm{~m}$, quite the marathon for an ant delivery service (FatEx?). Other perigynia have obscure dispersal modes. They rattle off the culms onto the soil and are perhaps carried by local water currents during rainfalls. Some seed fall and the population marches slowly across the habitat each year, culm length by culm length, expanding the local range. In urbanizing habitats, some sedges hitch rides with cars and construction vehicles as seeds carried in mud or on tires along roadways. Rapid spread in human dominated habitats is known for several species, adding to the rich flora of the disturbed habitats around us.

There are also important differences in Carex breeding systems. The subtle male and female florets on the flowering stems are sometimes clumped together, sometimes separated into single-sex spikelets arrayed down the culm. Some sedges are single-sex, dioecious. These differences are associated with a gradient of inbreeding and availability of pollen to adjacent plants. All sedges are wind pollinated, obviating the need for animal mutualists. This can encourage wide presence across temperate habitats. Asexual reproduction also varies among species; some are highly clonal such as the much used Carex pensylvanica. Others are clumped, cespitose, such as Carex stricta, and 
grow like lumps on a flat wetland platform. Attention to breeding system, clonal strategies, and dispersal syndromes help discriminate among the over 2,000 species if one looks closely.

The enormous speciation within the genus Carex has been a topic of much genetic research. Chromosome number varies enormously, diploid number varying from 12 to 124 . The cytogenetics in the genus is also remarkable. Chromosomes are holocentric, with centromeres seemingly spread across each chromosome length. When chromosomes fragment, many pieces can remain in the genome and are not lost during mitosis. With fragmentation and changed recombination dynamics, there maybe greater potential for many species to form. The simplicity of the flowering stems camouflage a remarkable cytogenetic novelty of fruit.

The role of Carex species in ecosystems is significant. In so many habitats, the impact on soil binding and formation and on modified water flows and storage is high. The role of Carex species in the food chain can be enormous. Many Lepidoptera, butterflies and moths, use the leaves for oviposition and for feeding. Many vertebrates across the range of the genus use the leaves and seeds as major food sources. Known herbivores include musk ox, elk, reindeer, snow geese, prairie dogs, and grasshoppers. I'm surprised that Ben and Jerry's haven't come out with the Carex fro-yo yet. Variation in nutrient content and defensive chemicals in sedges modify herbivory rates and specificity. Lemmings have been shown to discriminate among plants in Carex stands with different nutrient status, for example.

Relatively few Carex species are available from native plant nurseries for use in restoration plant pallettes. That adds to the cheapening of sedge biodiversity and landscape plans to the detriment of ecological function. We fear that the concentration on the showy, the easily identified, and the well-known will be an anchor slowing the improvement of restoration practice and the speed with which we can reiterate lost or damaged habitats. "Sedges have edges" is the sophomoric taxonomic clue we all learn in beginning botany courses. This is true, but it's time for the restoration profession to sharpen its own edge in reiterating the subtle but fabulous biodiversity around us.

\section{Recommended References}

Escudero, M., A.L. Hipp, M.J. Waterway and L.M. Valente. 2012. Diversification rates and chromosome evolution in the most diverse angiosperm genus of the temperate zone (Carex, Cyperaceae). Molecular Phylogenetics and Evolution 63:650-655.

Gilbert, B. and M.J. Lechowicz. 2004. Neutrality, niches, and dispersal in a temperate forest understory. Proceedings of the National Academy of Sciences of the United States of America 101:7651-7656.

Handel, S.N. 1976. Dispersal ecology of Carex pedunculata (Cyperaceae), a new North American myrmecochore. American Journal of Botany 63:1071-1079.

Hipp, A.L. 2008. Field guide to Wisconsin sedges: An introduction to the genus Carex (Cyperaceae). Madison, WI: University of Wisconsin Press.

Hipp, A.L., P.E. Rothrock and E.H. Roalson. 2009. The evolution of chromosome arrangements in Carex (Cyperaceae). The Botanical Review 75:96-109.

Reznicek, A.A. 1990. Evolution in sedges (Carex, Cyperaceae). Canadian Journal of Botany, 68:1409-1432.

Vellend, M., M.J. Lechowicz and M.J. Waterway. 2000. Germination and establishment of forest sedges (Carex, Cyperaceae): tests for home-site advantage and effects of leaf litter. American Journal of Botany 87:1517-1525.

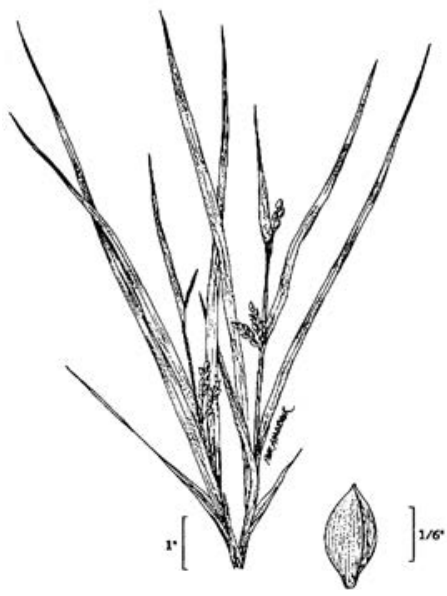

Carex abscondita. USDA-NRCS PLANTS Database. Wetland flora: Field office illustrated guide to plant species. USDA Natural Resources Conservation Service. 